\title{
Dynamic mechanical analysis and crystalline analysis of hemp fiber reinforced cellulose filled epoxy composite
}

\author{
Anand Palanivel ${ }^{1 *}$, Anbumalar Veerabathiran², Rajesh Duruvasalu', \\ Saranraj lyyanar ${ }^{1}$ and Ramesh Velumayil ${ }^{1}$
}

\author{
${ }^{1}$ Mechanical Engineering, Vel Tech Dr RR. \& Dr. SR University, Avadi, Chennai, Tamilnadu, India \\ ${ }^{2}$ Mechanical Engineering, Velammal College of Engineering \& Technology, Madurai, TN, India \\ *p.anand@ymail.com
}

\begin{abstract}
The Dynamic mechanical behavior of chemically treated and untreated hemp fiber reinforced composites was investigated. The morphology of the composites was studied to understand the interaction between the filler and polymer. A series of dynamic mechanical tests were performed by varying the fiber loading and test frequencies over a range of testing temperatures. It was found that the storage modulus (E') recorded above the glass transition temperature (Tg) decrease with increasing temperature. The loss modulus (E") and damping peaks (Tan $\delta$ ) values were found to be reduced with increasing matrix loading and temperature. Morphological changes and crystallinity of Composites were investigated using scanning electron microscope (SEM) and XRD techniques. The composites with Alkali and Benzoyl treated fibers has attributed enhanced DMA Results. In case of XRD studies, the composites with treated fibers with higher filler content show enhanced crystallinity.
\end{abstract}

Keywords: crystallinity, DMA, fiber treatments, hemp fiber, SEM, XRD.

\section{Introduction}

Manufacturing high performance engineering materials from renewable resources is one ambitious goal currently being pursued by researchers across the world. The ecological benefits of renewable raw materials are clearly saved valuable resources are environmentally sound and do not cause health problems. Natural fibers have already established a track record as simple filler material in automobile parts. Natural fibers like sisal, hemp, kenaf, jute, coir, oil palm fiber have been proved to be good reinforcement in thermosets and thermoplastic matrices ${ }^{[1-4]}$. Previous studies have proved hemp fibers to be an effective reinforcement in polymer matrix ${ }^{[5]}$.

The behavior of hybrid composites is a weighed sum of the individual components in which there is more favorable balance between the inherent advantages and disadvantages. In an interesting study dynamic mechanical analysis of natural fibre based hybrid composites was performed and observed that the hybridization of nature fibre improved thermal and dynamic mechanical properties ${ }^{[6]}$. Glass/banana hybrid poly- ester composites are subjected to dynamic mechanical analysis over a range of temperature and three different frequencies ${ }^{[7]}$. Similar work on mechanical and dynamic mechanical properties of sisal/glass hybrid composites reported increase in storage and loss modulus with hybridization of sisal/polyester with glass fibres ${ }^{[8]}$. Mixing natural fibres like hemp and kenaf with thermoplastics put Flex Form Technologies ${ }^{[9]}$ on the map and in the door panels of Chrysler's Sebring convertible. In Germany, after authorization of hemp cultivation led to development of flax/hemp (50:50) needle felt for high-segment cars. A landmark agreement between automobile giant Ford Automobiles supplier Visteon Automotive system and Kafue bio composites enhanced natural fibre composites applications in interior panels, linings and fittings. It is an important step towards higher performance of hybrid composites in automobiles applications. It is reported that presently, 27 components of a Mercedes S class are manufactured from natural fibre based composites with total weight of $43 \mathrm{~kg}^{[10]}$. The end of life vehicle ${ }^{[11]}$ directive in Europe states that by 2015, vehicles must be constructed of $95 \%$ recyclable materials, with $85 \%$ recoverable through reuse or mechanical recycling ${ }^{[12]}$. The researchers ${ }^{[13-18]}$ were carried out an improvement on dynamic mechanical properties of different polymeric composites system. The comparative studies in their investigation on the enhancement of damping in polymer composites have been suggested analyzing different fiber combinations. Extensive research work is being carried out regarding the visco elastic behavior of various polymer composites and blends ${ }^{[19,20]}$.

Dynamic Mechanical Analysis (DMA) is a sensitive technique that characterizes the mechanical responses of materials by monitoring property changes with respect to the temperature and/or frequency of oscillation. The technique separates the dynamic response of materials into two distinct parts: an elastic part (E') and a viscous or damping component (E"). The elastic process describes the energy stored in the system, while the viscous component describes the energy dissipated during the process. Mechanical loss factor $(\tan \delta$ ) is another useful parameter, which can be very useful ${ }^{[21-26]}$. The objective of this study was to investigate the influence of cellulose filler on dynamic mechanical behavior of Hemp/HFRCFE composites. HFRCFE composites using both (treated and untreated) Hemp fiber with cellulose filler is studied. Untreated HFRCFE was used in this study to obtain the elementary properties of Hemp-based HFRCFE with cellulose fillers. 


\section{Materials and Methods}

\subsection{Materials}

Hemp fibre mats were purchased from Sheeba fibers and handicrafts, Poovancode, Tamilnadu, India. The epoxy resin employed in the present study is LY556 and the hardener HY951 was purchased from the Modern Scientific Pvt Ltd, Chennai, Tamilnadu, India. LY556 resin is a bi-functional epoxy resin i.e., diglycidyl ether of biphenyl-A (DGEBA) and HY951 is an aliphatic primary amine, viz., triethylene tetra mine - TETA with the mixing ratio is $10: 1 \mathrm{w} / \mathrm{w}$.Lyocell Powder (1.7 decitex) with around $12 \mu \mathrm{m}$ was supplied by Simtek Lab Agencies, Navi Mumbai, India. Chemicals used for the surface modification of fiber are commercial Sodium Hydroxide and Benzoyl Chloride which were kindly supplied by Simtek Lab agencies, Navi Mumbai, India.

\subsection{Treatment of fiber}

First the received Hemp fibers are washed with distilled water to remove the surface dirt present in the fibers and then the fibers are dried in an air circulating oven at a temperature of $100^{\circ} \mathrm{C}$ until it gains a fixed value of weight. Then the fibers are named as raw hemp fibers shown in Figure 1.

\subsubsection{Bleaching treatment}

For this treatment $25 \mathrm{~g}$ Hemp fibers were added to a 2 L solution containing $320 \mathrm{~mL}(30 \%$; w/w) hydrogen peroxide and $1 \mathrm{~g}$ sodium hydroxide and heated at $85^{\circ} \mathrm{C}$ for $1 \mathrm{~h}^{[27,28]}$. During this process the fibers are cooked in the solution under gradual rise and fall of the temperature of the bath from $30{ }^{\circ} \mathrm{C}$ to $85^{\circ} \mathrm{C}$. This process of heating and cooling was done for a period of $1 \mathrm{~h}$. Finally, the cooked fibers are removed from the mixture at a temperature of $30{ }^{\circ} \mathrm{C}$. In order to remove excess mixture, the fibers are washed with distilled water. After washing, the fibers are again dried in an air circulating oven at a temperature of $100{ }^{\circ} \mathrm{C}$ until it gains constant weight ${ }^{[29]}$. Then the fibers are designated as bleached Hemp fibers.

\subsubsection{Chemical treatments-alkaline treatment}

Alkaline treatment or mercerization is one of the most used chemical treatments of natural fibers when used to reinforce thermoplastics and thermosets. The important modification done by alkaline treatment is the disruption of hydrogen bonding in the network structure, thereby increasing surface roughness. This treatment removes a certain amount of lignin, wax and oils covering the external surface of the fiber cell wall, depolymerises cellulose and exposes the short length crystallites ${ }^{[13]}$. Addition of aqueous sodium hydroxide $(\mathrm{NaOH})$ to natural fiber promotes the ionization of the hydroxyl group to the alkoxide ${ }^{[30]}$. A water-ethanol solution $(80: 20)$ is prepared $(6 \%$ of $\mathrm{NaOH})$ and stirred continuously for 1 hour. Later, fiber mats were immersed one by one in the solution. Finally after immersing all the fiber mats the object is left undisturbed for nearly 3 hours. Then the fiber mats are washed several times with distilled water followed by drying it at $80^{\circ} \mathrm{C}$ for 5 hours in a hot air oven $^{[31-34]}$. Then the fibers are designated as Treated Hemp fibers shown in Figure 2.

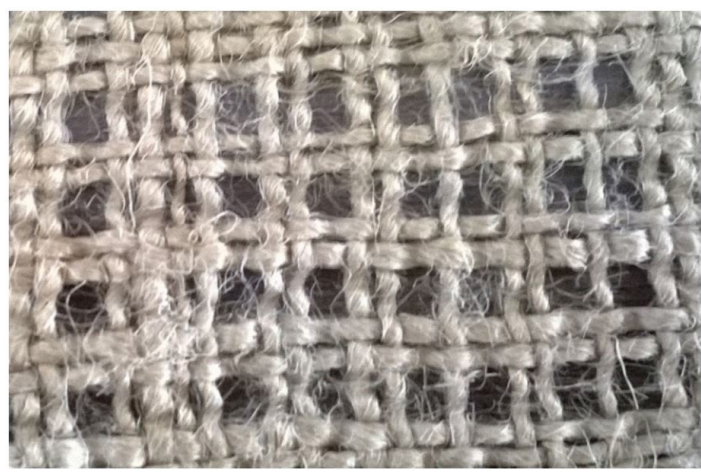

Figure 1. Raw hemp fiber mat.

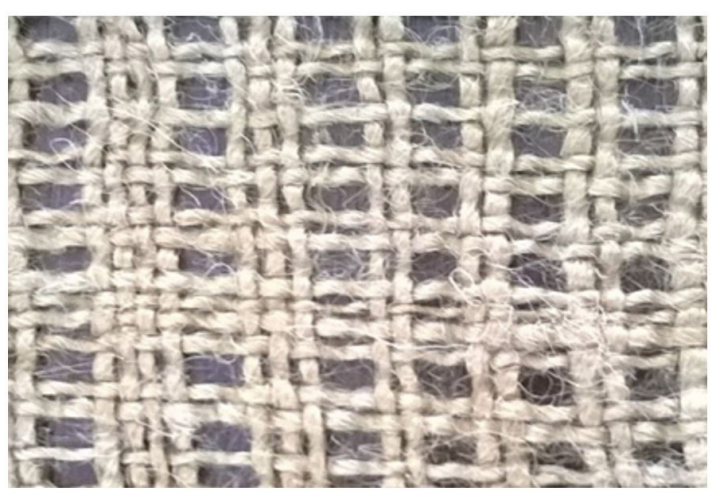

Figure 2. Treated hemp fiber mat.

\subsubsection{Benzoylation treatment}

Benzoylation is an important transformation in organic synthesis ${ }^{[35]}$. Benzoyl chloride is most often used in fiber treatment. Benzoyl chloride includes benzoyl $\left(\mathrm{C}_{6} \mathrm{H}_{5} \mathrm{C}=\mathrm{O}\right)$ which is attributed to the decreased hydrophilic nature of the treated fiber and improved interaction with the hydrophobic PS matrix ${ }^{[35]}$. Benzoylation of fiber improves fiber matrix adhesion, thereby considerably increasing the strength of composite, decreasing its water absorption and improving its thermal stability ${ }^{[36,37]}$. It was observed that the thermal stability of treated composites were higher than that of untreated fiber composites ${ }^{[36]}$. The fiber was initially alkaline pre-treated in order to activate the hydroxyl groups of the cellulose and lignin in the fiber; then the fiber was suspended in $10 \% \mathrm{NaOH}$ and benzoyl chloride solution for $15 \mathrm{~min}$. The isolated fibers were then soaked in ethanol for $1 \mathrm{~h}$ to remove the benzoyl chloride and finally was washed with water and dried in the oven at $80^{\circ} \mathrm{C}$ for $24 \mathrm{~h}$.

\subsection{Composite fabrication}

The composite material is fabricated by using hand layup technique ${ }^{[38]}$. Composite fabrication using double weave and non-woven Hemp mats $(150 \mathrm{~mm} \times 150 \mathrm{~mm} \times 1 \mathrm{~mm})$ was carried out in the square moulds of volume $350 \times 350 \times 3,350 \times 350 \times 6$ \& 350x350x10 $\mathrm{mm}^{3}$. Initially, the mould was polished and mould releasing agent was applied on its surface. Resin, hardener mixture and Synthetic Cellulose Powder (10:1:4.3) 
are spilled for every layer. Figure 3 shows the treated hemp fiber mat used for the material preparation.

Initially the fibres are dried in sun light to remove the moisture. The mould surface is cleaned and releasing agent (Wax) is applied. A thin layer of resin is also applied on the board. The woven roving NFRP are then completely filled with resin mixture, rolled to remove the entrapped air and to uniformly spread the mixture. In this way three layers of woven roving are placed one over the other to obtain top and bottom layers. A curing time of $24 \mathrm{Hrs}$ at room temperature is given for the structures to obtain good strength. After curing for $24 \mathrm{Hrs}$, the required composite was obtained. By the same fabrication procedure, composites of different configurations by varying the ratio of cellulose powder and epoxy resin were fabricated. The same fabrication process was then carried out for fibers which were chemically treated. Thus, untreated and treated composites were prepared. Figure 4 shows the fabricated composite material.

\section{Testing of Composites}

All the tests were carried out as per ASTM Standards at Central Institute of Plastics Engineering \& Technology, Chennai, India an ISO/IEC 17025:2005 - NABL Accredited Laboratory and ISO/IEC 17020 - NABCB Accredited Laboratory.

\subsection{Dynamic Mechanical Analysis (DMA)}

ADMA is a precision instrument used to measure mechanical and visco elastic properties both on rigid and soft solid materials, under controlled temperature settings. Concretely, storage modulus and loss modulus together with temperature are key parameters in the Frequency Sweep-Temperature Step test, while stress and strain parameters characterize the Stress-Strain test. The samples are mounted on a clamp with a stationary and a movable part connected to the drive motor. Thus, the motor affects directly the deformation of the sample. The way it works is simple: the drive motor delivers force or stress to the tested sample while an optical encoder measures the resulting displacement. Furthermore, it includes an air bearing of nitrogen to assure a smooth and continuous delivery of force without noise. The instrument used to perform Dynamic Mechanical Analysis tests in this investigation is the TA Q800 DMA.

To acquire and manage the results, this machine uses software which allows the user to visualize the obtained results, etc. To control the DMA, the user is able to choose between this software and the DMA's touch-screen when configuring test parameters. Basic instrument characteristics are presented in Table 1 and those focused specifically on our tests in Table 2.

Dynamic mechanical analysis (DMA) of HFRCFE composites was performed with a single cantilever mode at constant amplitude of $15 \mu \mathrm{m}$ with $1 \%$ strain rate over a frequency of $0.1 \mathrm{~Hz}$ to $100 \mathrm{~Hz}$ purging liquid nitrogen. The heating rate was $5^{\circ} \mathrm{C} / \mathrm{min}$. Before each measurement, the DMA instrument was calibrated to have the correct clamp position and clamp compliance. The specimen dimensions were $35 \mathrm{~mm} \times 13 \mathrm{~mm} \times 3 \mathrm{~mm}$. The DMA experiments were carried out in the temperature range from

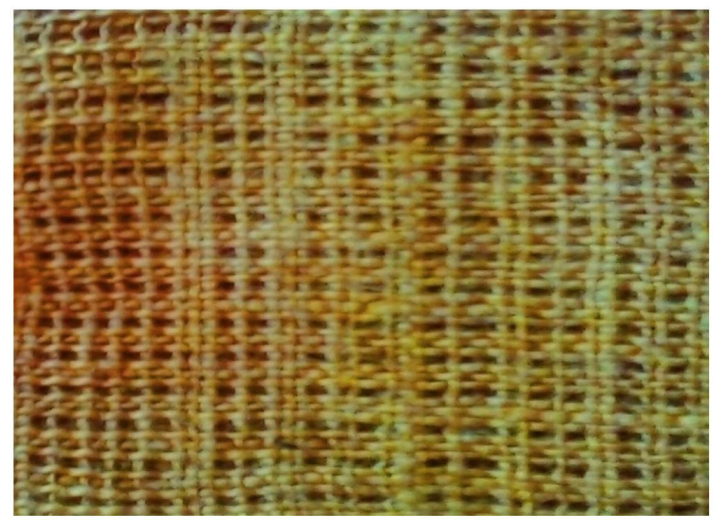

Figure 3. Treated hemp fiber mat.

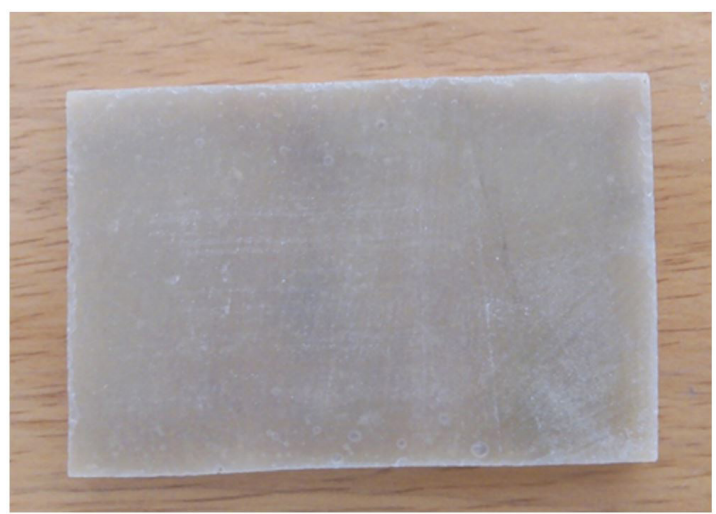

Figure 4. Fabricated HFRCFE specimens.

Table 1. Basic instrument characteristics

\begin{tabular}{lc}
\hline $\begin{array}{c}\text { Operating environment } \\
\text { conditions }\end{array}$ & $\begin{array}{c}\text { Temperature: } \mathbf{1 5 - 3 0}{ }^{\circ} \mathbf{C}, \\
\text { Relative Humidity: } \mathbf{5 - 8 0} \% \\
\text { (non condensing) }\end{array}$ \\
\hline Temperature Range & -145 to $600{ }^{\circ} \mathrm{C}$ \\
Displacement Range & $25 \mathrm{~mm}$ \\
Loading & 0.001 to $18 \mathrm{~N}$ \\
\hline
\end{tabular}

Table 2. Specific characteristics of rectangular samples.

\begin{tabular}{lc}
\hline \multicolumn{1}{c}{ Clamp } & \multicolumn{1}{c}{ 3 Point Bending } \\
\hline Sample Length & $35 \mathrm{~mm}$ (distance between support struts) \\
Sample Width & $13 \mathrm{~mm}$ (varies slightly for each sample) \\
Sample Thickness & $3 \mathrm{~mm}$ (varies slightly for each sample) \\
\hline
\end{tabular}

$-30^{\circ} \mathrm{C}$ to $200^{\circ} \mathrm{C}$ under ASTM D4065 standards. The storage modulus (E') \& loss modulus (E") and the mechanical loss factor ( $\tan$ delta), as a function of temperature $(T)$, were determined by dynamic mechanical analyzer were plotted versus temperature.

\subsection{X-Ray Diffraction (XRD) study}

XRD measurements were made using Philips X'Pert powder diffraction system (Philips Analytical, The Netherlands) equipped with a vertical goniometer in the Bragg-Brentano focusing geometry. The X-ray generator was operated at $40 \mathrm{kV}$ and $50 \mathrm{~mA}$, using the $\mathrm{CuK \alpha}$ line at $1.54056 \AA$ as 
the radiation source. Each powdered specimen was packed in a specimen holder made of glass. In setting up the specimen and apparatus, co planarity of the specimen surface with the specimen holder surface, and the setting of the specimen holder at the position of symmetric reflection geometry were ensured. The powders were passed through a 100 mesh sieve and were placed into the sample holder by the side drift technique ${ }^{[39]}$. The holder consisted of a central cavity. In order to prepare a sample for analysis, a glass slide was clipped to the top face of the sample holder so as to form a wall. The powder sample was filled into the holder, gently tapped and used for XRD measurement. $10 \mathrm{mg}$ of each sample was scanned at $25^{\circ} \mathrm{C}$ from $10^{\circ} \mathrm{C}$ to $70^{\circ} \mathrm{C}(2 \theta)$ and in step size of 0.020 and count time of $2.00 \mathrm{~s}$, using an automatic divergence slit assembly and a proportional detector. Relative intensities were read from the strip charts and corrected to fixed slit values. The Percentage crystallinity and crystallinity index was calculated as followed in (1).

$$
\% C r=\frac{I_{22}}{I_{22}+I_{18}} \times 100 \quad \text { C.I. }=\frac{I_{22}-I_{18}}{I_{22}}
$$

$\% \mathrm{Cr}-$ Percentage of Crystallinity, C.I. - Crystallinity Index, $\mathrm{I}_{22}$ - Relative Intensity @ $22^{\circ} \& \mathrm{I}_{18}$ - Relative Intensity @ $18^{0}$.

\subsection{Morphological study (Scanning Electron Microscope - SEM)}

To illustrate the effect of surface treatment of the fibre, the failure surfaces of the specimens subjected to test were analyzed using a JEOL scanning electron microscope (SEM). In SEM a fine probe of electrons scans the surface of the sample and the signals emanating from the incident site are processed and quantized. All specimens were sputtered with $10 \mathrm{~nm}$ layer of gold prior to SEM observations. Each specimen was mounted on the aluminum holder of the microscope using double sided electrical conduction carbon adhesive tabs. The accelerating voltage of 5-15 $\mathrm{kV}$ was employed. The SEM analyses of both raw and surface treated fibre reinforced composites were compared.

\section{Results and Discussion}

The Table 3 shows the seven specimens having different compositions with three samples each were tested in DMA, XRD \& SEM Analysis.

\subsection{Dynamic mechanical analysis}

\subsubsection{Storage modulus (E')}

The dynamic storage modulus (E') is defined as the stress in phase with the strain in a sinusoidal shearing deformation divided by the strain ${ }^{[40]}$. The variation in the storage modulus as a function of temperature for the studied composites is given in Figure 5. As the temperature increases, E' decreases for all composites and this can be attributed to the increase in the molecular mobility of the polymer chains ${ }^{[41]}$. A prominent increase in storage modulus of the matrix in the elastomeric region with the incorporation of fibers is expected due to an increase in stiffness of the matrix with the reinforcing effect imparted by the fibers. 8 There is a clear increase in E" with filler loading and the maximum E" values were found for the composite with the optimum cellulose filler content of all samples (i.e., XHFRCFE). This may be associated with the strong filler/matrix interaction and the elastic modulus of the treated hemp fiber ${ }^{[8,40-42]}$. The drop in the modulus (E') on passing through the glass transition temperature is comparatively less for reinforced composites than for unreinforced resin. This can be attributed to the combination of the hydrodynamic effects of the fibers embedded in a visco elastic medium and to the mechanical restraint introduced by the filler at the high concentrations, which reduce the mobility and deformability of the matrix. Other authors have also reported similar observations ${ }^{[43]}$. at higher temperatures any water molecules adhering on to the fiber will get evaporated making the fiber stiffer.

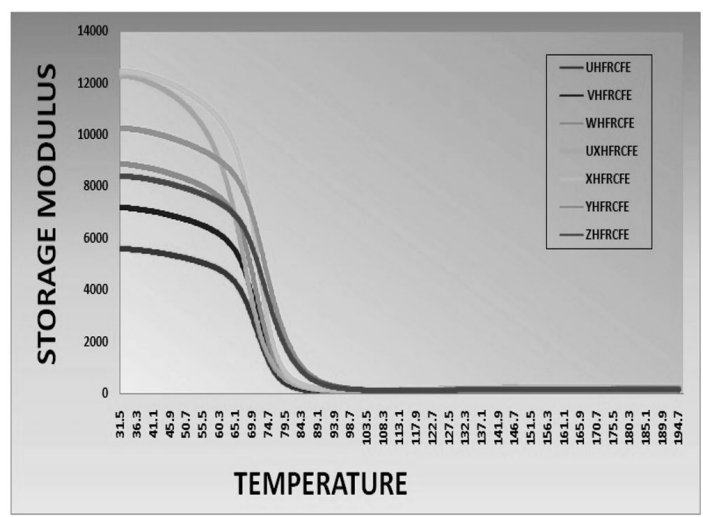

Figure 5. Effect of temperature on storage modulus.

Table 3. Composition of different specimen (Percentage of Weight).

\begin{tabular}{ccccccc}
\hline S.No & Specimen & Hemp (\%) & $\begin{array}{c}\text { Cellulose Powder } \\
\mathbf{( \% )}(\mathbf{1})\end{array}$ & Epoxy resin (\%) (2) & Hardener (\%) (3) & Proportion 3:2:1 \\
\hline 1 & U HFRCFE & 8 & 34.25 & 52.5 & 5.25 & $10: 1: 6.5$ \\
2 & V HFRCFE & 8 & 31.5 & 55 & 5.5 & $10: 1: 5.7$ \\
3 & W HFRCFE & 8 & 28.75 & 57.5 & 5.75 & $10: 1: 5$ \\
4 & X HFRCFE & 8 & 26 & 60 & 6 & $10: 1: 4.3$ \\
5 & Y HFRCFE & 8 & 23.25 & 62.5 & 6.25 & $10: 1: 3.7$ \\
6 & Z HFRCFE & 8 & 20.5 & 65 & 6.5 & $10: 1: 3.2$ \\
7 & UX (Untreated) HFRCFE & 8 & 26 & 60 & 6 & $10: 1: 4.3$ \\
\hline
\end{tabular}


Air-dried cellulose is rather resistant to mechanical impact and a large amount of mechanical energy has to be spent in order to destroy the macroscopic and microscopic structure. This ultimately contributes to the improved modulus of the composite at high temperatures.

\subsubsection{Loss modulus (E")}

The loss modulus (E") is defined as the stress $90^{\circ}$ out-of-phase with the strain divided by the strain. It is a measure of the energy dissipated as heat per cycle under deformation, i.e., the viscous response of the material ${ }^{[40]}$. Figures 6 show the variation in E" with the temperature for the different composites. From these figures, it is clear that the incorporation of treated fiber causes a broadening of the loss modulus peak. This may be attributed to the inhibition of the relaxation process within the composites as a consequence of a higher number of chain segments upon filler addition ${ }^{[44]}$. There is an apparent shift in $\mathrm{T}_{\mathrm{g}}$ toward higher temperatures on increasing the filler content and the overall filler loading. This is primarily attributed to the segmental immobilization of the matrix chain at the fiber surface ${ }^{[45]}$. The loss modulus in the transition region is also higher for composites with higher filler content, which may be due to an increase in internal friction, promoting energy dissipation. The high modulus glass fibers introduce constraints on the segmental mobility of the polymeric molecules at the relaxation temperatures, but, probably, there are also other factors that lead to energy dissipation ${ }^{[46]}$. It can be observed that, for higher filler content, the loss modulus curve spreads over a wider distribution and shows a higher peak. This effect can be a consequence of the inhibition/ restriction of the relaxation process of the chain segments in the composites or due to an increase in the rigidity of chain segments, increasing material heterogeneity ${ }^{[47]}$. A higher peak height may be associated to a poor interface ${ }^{[48]}$. However, in general, it may also be attributed to an increase in the mobility of the polymer chains ${ }^{[35]}$. The width of the relaxation curve is characterized by the $\beta$ factor of the Kohlrausch-Williams- Watts equation (KWW). A low $\beta$ value implies a wider distribution, whereas a $\beta$ value close to the unity means a perfectly narrow relaxation spectrum ${ }^{[4,50]}$. An increase in free volume usually results in a decrease in the number of cross-linking sites of the polymeric matrix, because there is less cross- linked space between fiber and filler incorporated epoxy matrix. Also, a tendency toward a $\alpha$-transition shift is noted for higher temperatures increasing the filler content. The increase in width of the loss modulus curve is taken to represent the presence of an increased range of order. The greater constraints on the amorphous phase could give rise to higher or broader glass transition behavior Figure shows the maximum peak width is found to be for the composites with $43 \%$ filler loading.

\subsubsection{Damping parameters $(\tan \delta)$}

The ratio between the loss modulus (E") and the storage modulus (E') is called the mechanical loss factor, or $\tan \delta$. Figure 7 delineates the effect of temperature on $\tan \delta$. Improvement in interfacial bonding in composites occurs as observed by the lowering in $\tan \delta$ values. The damping properties of the material give the balance between the elastic and viscous phases in a polymeric structure ${ }^{[51]}$. In composites, damping is influenced by the incorporation,

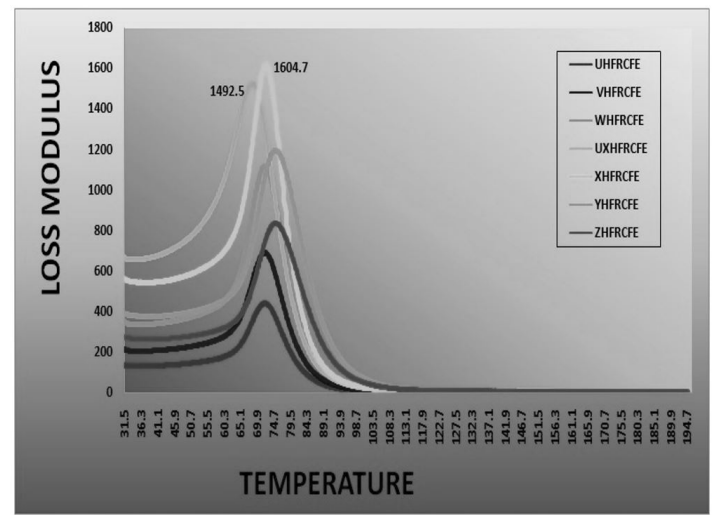

Figure 6. Effect of temperature on loss modulus

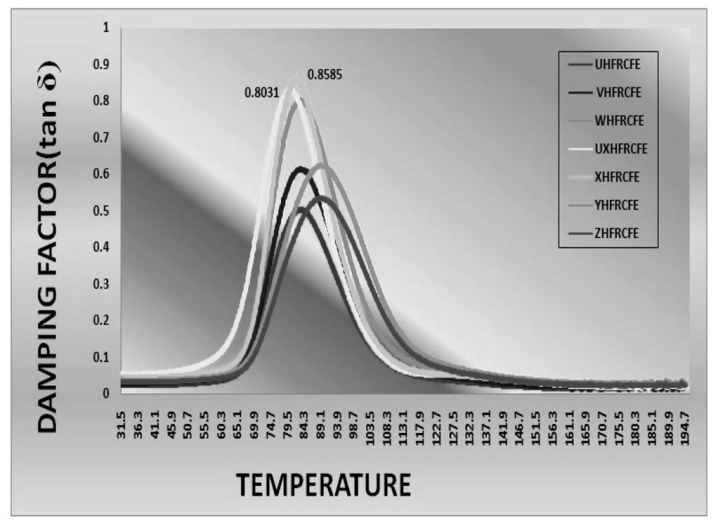

Figure 7. Effect of temperature on damping factor.

type and distribution of fibers, as well as the filler/matrix interaction and the void content ${ }^{[52-56]}$. All materials exhibit a relaxation process, which is associated with the glass-rubber transition of the matrix. It has been observed that as the temperature increases, the damping values pass through a maximum in the transition region and then decrease in the rubbery region. This relaxation process, denoted as $\alpha$, involves the release of cooperative motions of chains between cross links. Below Tg, damping is low because, in this region, the chain segments are in the frozen state. Hence, the deformations are primarily elastic and the molecular slips resulting in the viscous flow are low. Also, in the rubbery region, the molecular segments are quite free to move and hence damping is low and thus there is no resistance to flow ${ }^{[4,57]}$. However, in the transition region, the molecular chains begin to move and every time a frozen segment begins to move its excess energy is dissipated as heat. In fact, a frozen-in segment in the glassy state can store more energy for a given deformation than a rubbery segment, which can move freely. In a region where most of the chain segments take part in a cooperative motion under a given deformation, maximum damping will occur ${ }^{[2,44,58]}$.

The position and height of the $\tan \delta$ peak are indicative of the structure and properties of a particular composite material. Generally, composites have considerably less damping in the transition region compared to neat resin because the fibers 
and fillers carry a greater amount of the load and allow only a small part of it to strain the interface ${ }^{[45]}$. Therefore, energy dissipation will occur in the polymer matrix at the interface and a stronger interface allows less dissipation. This may be due to a restriction of the movement of the polymer molecules due to the incorporation of the stiff fibers ${ }^{[47]}$. As in the case of the E" curves, the tan $\delta$ curves of the composites shift towards higher values for higher overall and treated fiber content. In general, this is indicative of a poor interface. Since a lower peak height indicates a good interfacial adhesion ${ }^{[59]}$, according to the results shown in this study other factors contribute to the softening of the interface. Generally, composites containing less fiber content exhibit higher peak heights. One reason for this may be that there is less matrix by volume with higher filler content, and there is more energy at the interface because of the increase in the interfacial area. The matrix dissipates more energy than composites, because the fibers carry a greater amount of the load, dissipating a small part of it to strain the interface. The width of the tan $\delta$ peak of the composites also becomes broader upon fiber treatments. At lower fiber concentrations, the packing of fibers will become inefficient leading to matrix-rich regions and therefore the matrix is not restrained by sufficient fibers and highly localized strains will occur ${ }^{[47]}$. Higher value was obtained for the matrix more cross linking sites, as a consequence, a more heterogeneous system is obtained.

\subsection{X-ray diffraction analysis}

$\mathrm{X}$-ray diffraction studies were performed on X-ray diffractometer. It is evident from Table 4 that UXHFRCFE at $2 \theta$ scale gave peaks at 22.0 and 18.0 with relative intensity is 1370 and 819 respectively. Percentage crystallinity $(\% \mathrm{Cr})$ and crystallinity index (C.I.) of UXHFRCFE are 62.59 and 0.40 respectively whereas percentage crystallinity of Surface treated HFRCFE Composites were $71.59,68.31,66.03,64.52,63.93$ and 63.18 Whereas crystallinity index of Surface treated HFRCFE Composites are $0.6,0.54,0.49,0.45,0.44$ and 0.42 respectively. The counter reading at peak intensity at $22^{\circ}$ is said to represent the crystalline material and the peak intensity at $18^{\circ}$ corresponds to the amorphous material in cellulose ${ }^{[60,61]}$, Percentage Crystallinity ${ }^{[62]}$ and crystalline index ${ }^{[63,64]}$ were calculated and tabulated in Table 4 . A poor crystallinity index in case of untreated hemp fibers reinforced in cellulose filled epoxy matrix means poor order of cellulose crystals to the fiber axis during treatments, indicated by the lower crystallinity index. Thus clearly indicate that cellulose crystals are better oriented in hemp fibers followed by alkali and benzoyl treated hemp fibers reinforced in cellulose filled epoxy composites. The graph of raw and surface treated HFRCFE Composites is shown in Figures 8-10.

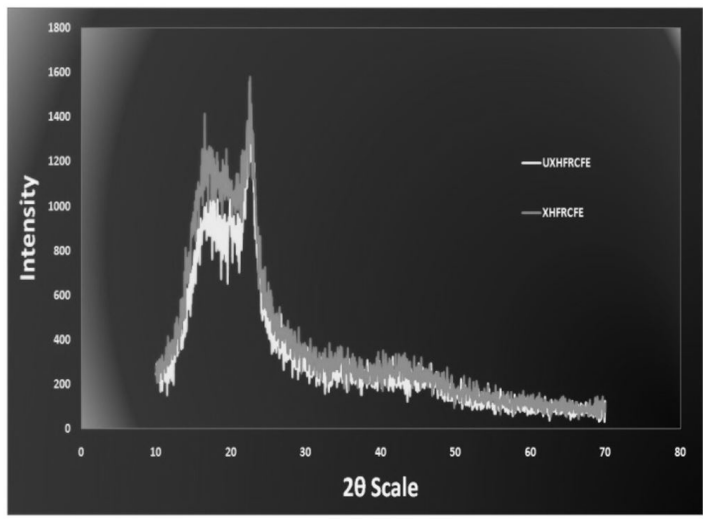

Figure 8. XRD plots of surface treated and raw XHFRCFE.

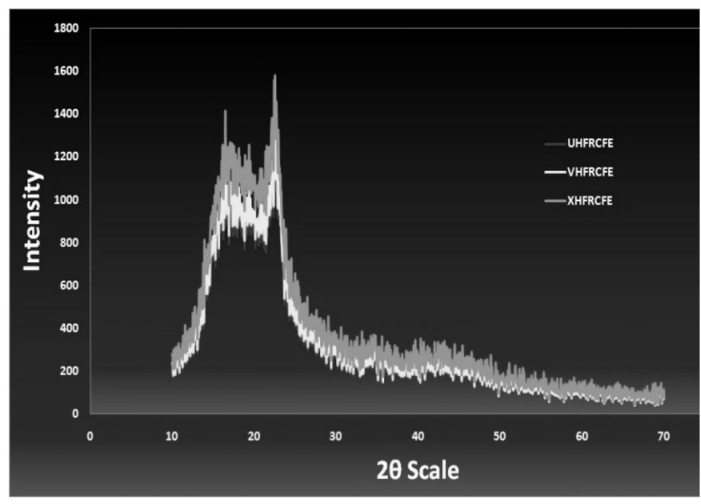

Figure 9. XRD plots of U, V \& XHFRCFE composites.

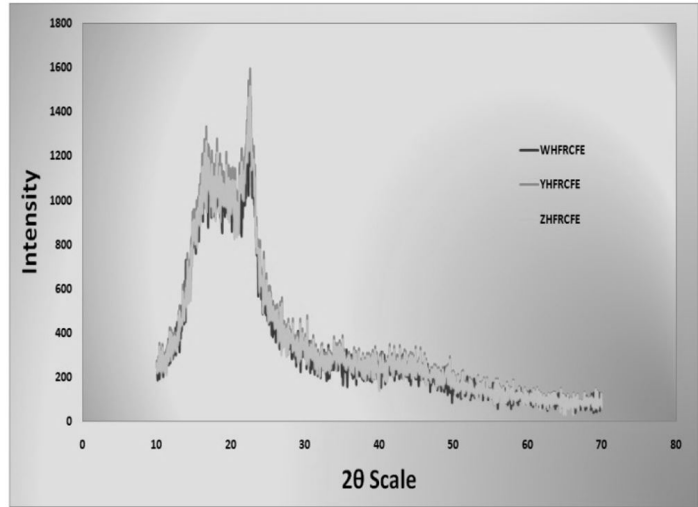

Figure 10. XRD plots of W, Y \& Z composites.

Table 4. XRD data of untreated and treated HFRCFE composites.

\begin{tabular}{|c|c|c|c|c|c|}
\hline S.No & Specimen & $I_{22 @} 2 \theta$ & $I_{18 @} 2 \theta$ & $\% \mathrm{Cr}$ & C.I \\
\hline 1 & U HFRCFE & 1283 & 724 & 63.93 & 0.44 \\
\hline 2 & V HFRCFE & 1351 & 695 & 66.03 & 0.49 \\
\hline 3 & W HFRCFE & 1422 & 782 & 64.52 & 0.45 \\
\hline 4 & X HFRCFE & 1625 & 645 & 71.59 & 0.6 \\
\hline 5 & Y HFRCFE & 1595 & 740 & 68.31 & 0.54 \\
\hline 6 & Z HFRCFE & 1515 & 883 & 63.18 & 0.42 \\
\hline 7 & UX (Untreated) HFRCFE & 1370 & 819 & 62.59 & 0.4 \\
\hline
\end{tabular}




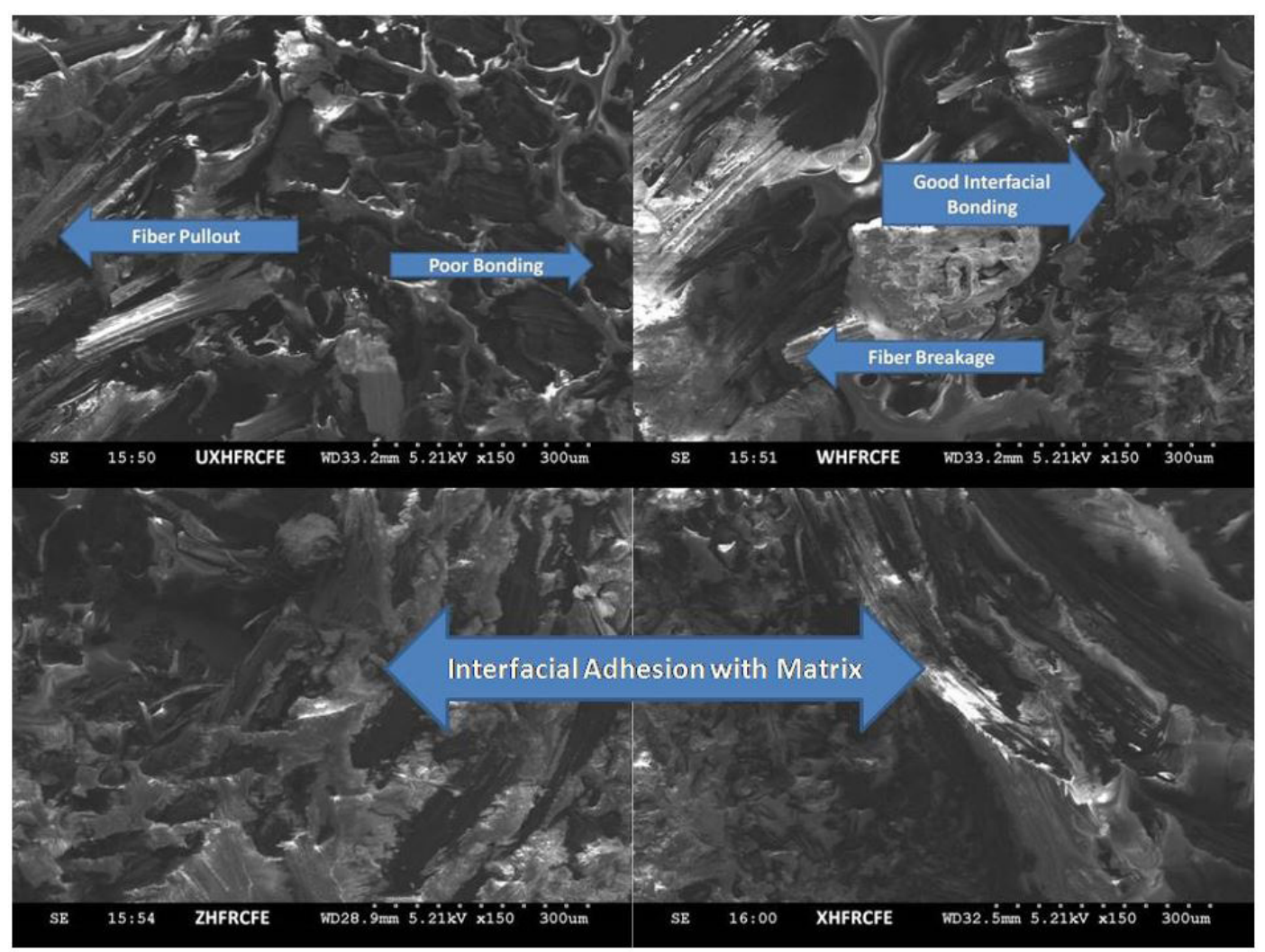

Figure 11. SEM photographs of raw and treated HFRCFE composites.

X-ray results for treated composites which show an increase in the 'crystallinity' index indicate improvement in the order of the crystallites as the cell wall thickens upon surface treatments and increase in the filler content. These treatments were reported to reduce the proportion of crystalline material present in plant fibers, and increase in filler loading as observed by several researchers ${ }^{[65]}$. The increase of crystallinity index indicated that the fillers in matrix induced the crystallinity and it increase due to the removal of amorphous materials like hemicellulose, lignin, and some other non-cellulosic material by surface treatment of fibers.

\subsection{Morphological analysis (SEM Analysis)}

Scanning electron microscopic (SEM) provide an excellent technique for the study of surface morphology of cellulose filled epoxy matrix reinforced with treated hemp fibers. Surface morphologies of untreated and surface treated HFRCFE Composites are presented in Figure 11. These results suggest that cellulose in raw Hemp fiber is held together by means of binding components such as lignin, pectin, etc, which are removed after treatments. On the other hand, treated fiber showed a comparatively smoother surface with narrow fiber-thickness. Surface morphologies of treated HFRCFEs were attributed to the removal of lignin, pectin and hemicelluloses and agree with our observed surface structures.
The SEM Examinations of fractured surfaces of untreated fiber based composites with cellulose fillers are presented in Figure Composites with less percentage filler content revealed poor interfacial bonding. Micrographs indicated fiber pull out, debonding, delamination and fiber breakage. On the other hand treated fiber based composites showed much less fiber pull out indicating the better interfacial adhesion between fiber and matrix due to treatment.

\section{Conclusions}

In this article dynamic mechanical properties of hemp fiber reinforced cellulose filled epoxy hybrid composites are described. The effect of hybridization on the dynamic mechanical properties was studied in detail (Figure 12, 13). As expected, the storage and loss modulus decreased with the increase in temperature, which is associated with a softening of the matrix at higher temperatures.

The storage modulus increased with increasing filler loading and this was due to the reinforcement effect imparted by the fillers which are more rigid than the matrix. The loss modulus curves were found to distribute over a wider range and reach higher peak values for higher filler content. These curves, which are indicative of the dissipated energy, were found to be shifted to higher positions following the incorporation of more cellulose fillers into the composites. The incorporation of treated hemp fibers also caused a broadening of the loss modulus peak which was attributed to 


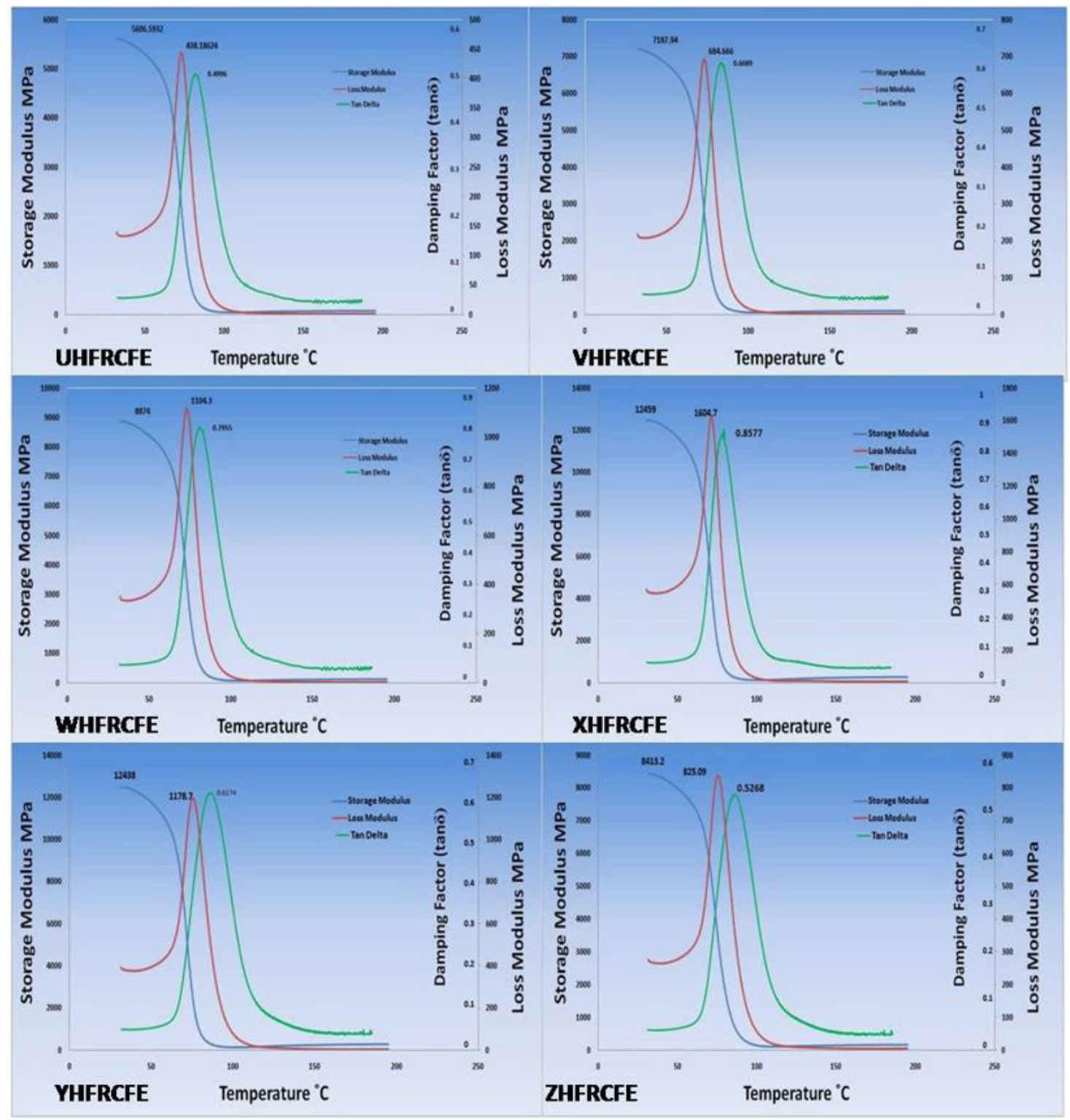

Figure 12. DMA analysis of HFRCFE composites.

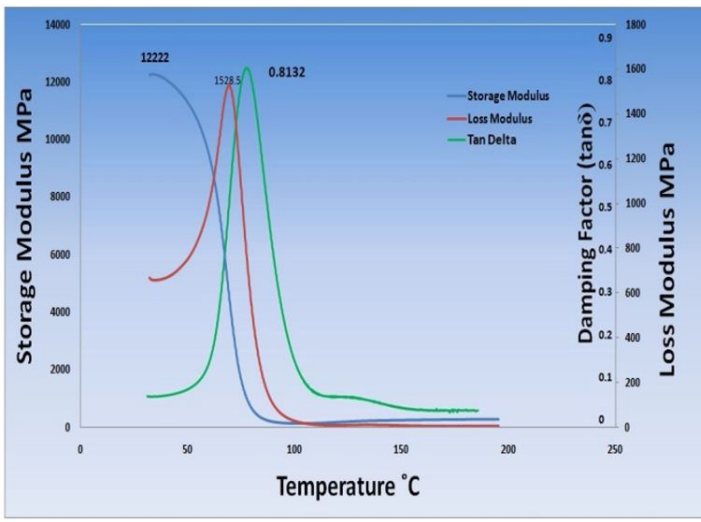

Figure 13. DMA analysis of UXHFRCFE composites. the inhibition of the relaxation process within the composites. The higher loss modulus at the relaxation temperature was associated with an increase in internal friction which enhances energy dissipation. Additionally, despite the presence of high-modulus cellulose fillers, which introduce constraints on the segmental mobility of the polymeric molecules at the relaxation temperature, there are other factors that lead to energy dissipation. There was a shift in the glass transition towards higher temperatures on increasing the overall filler loading and the treated fiber content. This is because of restrictions imposed on the mobility of the polymer molecules at the interface. The highest activation energy values were obtained for the composites with higher glass fiber content.

It is believed that the increase in the crystallinity index obtained by X-ray diffraction is in actual fact an increase of 
the order of the crystallite packing rather than in increase in the intrinsic crystallinity. The surface of hemp fiber becomes rougher after treatments in comparison with smooth and clear surface of raw hemp fibers. The removal of surface impurities on plant fibers may be an advantage for fiber to matrix adhesion as it may facilitate both mechanical interlocking and the bonding reaction due to the exposure of the hydroxyl groups to chemicals such as resins and fillers. Better adhesion between filler and matrix, as evidenced by scanning electron microscopy, was found in the case of composites with treated fiber and filler content, while the composite materials without fiber treatments showed debonding and agglomeration of fiber, thereby decreasing their interfacial adhesion. Removal of non-cellulosic compounds is also suspected to increase the amount of $\mathrm{OH}$ groups exposed on the fiber surface, which could assist in mechanical enlargement with the matrix in the presence of cellulose filler, as evidenced by the increase in composites strength.

\section{Abbreviations}

DMA - Dynamical Mechanical Analysis, SEM-Scanning Electron Microscope, XRD - X Ray Diffraction, HFRCFE-Hemp Fiber Reinforced Cellulose Filled Epoxy Composites.

\section{References}

1. Joseph, K., Thomas, S., \& Pavithran, C. (1996). Effect of chemical treatment on the tensile properties of short sisal fiber-reinforced polyethylene composites. Polymer, 37(23), 5139-5145. http://dx.doi.org/10.1016/0032-3861(96)00144-9.

2. Varma, I. K., Anantha Krishnan, S. R., \& Krishnamoorthy, S. (1989). Comp of glass/modified jute fabric and unsaturated polyester. Composites, 20(4), 383-388. http://dx.doi. org/10.1016/0010-4361(89)90664-2.

3. Geethamma, V. G., Thomas Mathew, K., Lakshminarayanan, R., \& Thomas, S. (1998). Composite of short coir fibers and natural rubber: effect of chemical modification, loading and orientation of fiber. Polymer, 39(6-7), 1483-1491. http://dx.doi. org/10.1016/S0032-3861(97)00422-9.

4. Sreekala, M.S., Kumaran, M.G., \&Thomas, S. (1997). Oil palm fibers: morphology, chemical composition, surface modification and mechanical properties. Journal of Applied Polymer Science, 66(5). 821-835. http://dx.doi.org/10.1002/ (SICI)1097-4628(19971031)66:5<821::AID-APP2>3.0.CO;2-X.

5. Aziz, S. H., \& Ansell, M. P. (2004). The effect of alkalization and fibre alignment on the mechanical and thermal properties of kenaf and hemp bast fibre composites: Part 1-polyester resin matrix. Composites Science and Technology, 64(9), 1219-1230. http://dx.doi.org/10.1016/j.compscitech.2003.10.001.

6. Jacob, M., Francis, B., Thomas, S., \& Varughese, K. T. (2006). Dynamical mechanical analysis of sisal/oil palm hybrid fiberreinforced natural rubber composites. Polymer Composites, 27(6), 671-680. http://dx.doi.org/10.1002/pc.20250.

7. Pothan, L. A., George, C. N., John, M. J., \& Thomas, S. (2010). Dynamic mechanical and dielectric behavior of banana-glass hybrid fiber reinforced polyester composites. Journal of Reinforced Plastics and Composites, 29(8), 1131-1145. http:// dx.doi.org/10.1177/0731684409103075.

8. Ornaghi, H. L. Jr, Bolner, A. S., Fiorio, R., Zattera, A. J., \& Amico, S. C. (2010). Mechanical and dynamic mechanical analysis of hybrid composites molded by resin transfer molding.
Journal of Applied Polymer Science, 118(2), 887-896. http:// dx.doi.org/10.1002/app.32388.

9. Ning, H. (2012). Composites and their applications. Croatia: Intech Open. http://dx.doi.org/10.5772/3353.

10. Sreekumar, P. A. (2008). Matrices for natural-fibre reinforced composites. In K. Pickering (Ed.), Properties and performance of natural-fibre composite. Boca Raton: CRC Press, Taylor \& Francis Group.

11. Selvin, T. P., Kuruvilla, J., \& Sabu, T. (2004). Mechanical properties of titanium dioxide-filled polystyrene micro composites. Materials Letters, 58(3), 281-289. http://dx.doi. org/10.1016/S0167-577X(03)00470-1.

12. Peijs, T. (2003). Composites for recyclability. Materials Today, 6(4), 30-35. http://dx.doi.org/10.1016/S1369-7021(03)00428-0.

13. Wambua, P., Ivens, J., \& Verpoest, I. (2003). Natural fibres: can they replace glass in fibre reinforced plastics? Composites Science and Technology, 63(9), 1259-1264. http://dx.doi. org/10.1016/S0266-3538(03)00096-4.

14. Shihong, B., Benlian, Z., Qiyun, Z., \& Xianrong, B. (1994). A new kind of super-hybrid composite material for civil use - ramie fibre/Al. Composites, 25(3), 225-228. http://dx.doi. org/10.1016/0010-4361(94)90020-5.

15. Park, J. M., Son, T. Q., Jung, J. G., \& Hwang, B. S. (2006). Interfacial evaluation of single ramie and kenaf fiber/epoxy resin composites using micromechanical test and non-destructive acoustic emission. Composite Interfaces, 13(2-3), 105-129. http://dx.doi.org/10.1163/156855406775997051.

16. Nam, S., \& Netravali, A. N. (2006). Green composites IPhysical properties of ramie fibers for environment-friendly green composites. Fibers and Polymers, 7(4), 372-379. http:// dx.doi.org/10.1007/BF02875769.

17. Nam, S., \& Netravali, A. N. (2006). Green composites II Environment-friendly, biodegradable composites using ramie fibers and soy protein concentrate (SPC) resin. Fibers and Polymers, 7(4), 380-388. http://dx.doi.org/10.1007/BF02875770.

18. Kishi, H., \& Fujita, A. (2008). Wood-based epoxy resins and the ramie fiber reinforced composites. Environmental Engineering and Management Journal, 7, 517-523.

19. Kalia, S., Kaith, B. S., \& Kaur, I. (2009). Pre-treatments of natural fibers and their application as reinforcing material in polymer composites - a review. Polymer Engineering and Science, 49(7), 1253-1272. http://dx.doi.org/10.1002/pen.21328.

20. Monteiro, S. N., Margem, F. M., Rodriguez, R. J. S., \& Souza, D. (2008). Dynamic mechanical behavior of ramie fiber reinforced polyester matrix composites In Proceedings of the 63rd International Congress of the Brazilian Association for Metallurgy and Materials - ABM (pp. 1-10). São Paulo: ABM.

21. Sharma, J., \& Bapat, M. N. (2014). Dynamic mechanical behavior and dielectric properties of rice husk filled low density polyethylene composites with/without flyash cenosphere. Nova Journal of Engineering and Applied Sciences, 3(3). 1-18. http:// dx.doi.org/10.20286/jeas.v3i3.22.

22. Han, Y. H., Han, S. O., Cho, D., \& Kim, H.-I. (2008). Dynamic Mechanical Properties of Natural Fiber/Polymer Biocomposites: the Effect of Fiber Treatment with Electron Beam. Macromolecular Research, 16(3), 253-260. http://dx.doi. org/10.1007/BF03218861.

23. Margem, F. M., Monteiro, S. N., Bravo, J., No., Rodriguez, R. J. S., \& Soares, B. G. (2010). The dynamic-mechanical behavior of epoxy matrix composites reinforced with ramie fibers. Revista Matéria, 15(2), 164-171. http://dx.doi.org/10.1590/ S1517-70762010000200012.

24. Mehdi, B., Mehdi, T., Ghanbar, E., \& Robert, H. F. (2004). Dynamic mechanical analysis of compatibilizer effect on the mechanical properties of wood flour-high-density polyethylene composites. IJE Transactions B, Applications, 17(1), 95-104. 
25. Flaifel, M. H., Ahmad, S. H., Hassan, A., Bahri, S., Tarawneh, M. A., \& Yu, L.-J. (2013). Thermal conductivity and dynamic mechanical analysis of NiZn ferrite nanoparticles filled thermoplastic natural rubber nano composite. Composites. Part B, Engineering, 52, 334-339. http://dx.doi.org/10.1016/j. compositesb.2013.04.021.

26. Jawaid, M., Abdul Khalil, H. P. S., Hassan, A., Dungani, R., \& Hadiyane, A. (2013). Effect of jute fibre loading on tensile and dynamic mechanical properties of oil palm epoxy composites. Composites. Part B, Engineering, 45(1), 619-624. http://dx.doi. org/10.1016/j.compositesb.2012.04.068.

27. Maleque, M. A., Belal, F. Y., \& Sapuan, S. M. (2007). Mechanical properties study of pseudo-stem banana fiber reinforced epoxy composite. Arabian Journal for Science and Engineering, 32(2B), 359-364

28. Karam, G. (1994). Effect of fiber - fiber interaction on strength properties of short fiber reinforced cements. Journal of Composites Technology and Research, 16(2), 154-160. http:// dx.doi.org/10.1520/CTR10405J.

29. Mohanty, A. K., Misra, M., \& Drzal, L. T. (2001). Surface modifications of natural fibers and performance of the resulting biocomposites: An overview. Composite Interfaces, 8(5), 313343. http://dx.doi.org/10.1163/156855401753255422.

30. Agrawal, R., Saxena, N. S., Sharma, K. B., Thomas, S., \& Sreekala, M. S. (2000). Activation energy and crystallization kinetics of untreated and treated oil palm fibre reinforced phenol formaldehyde composites. Materials Science and Engineering A, 277(1-2), 77-82. http://dx.doi.org/10.1016/ S0921-5093(99)00556-0.

31. Katz, J. (1977). US Patent $N^{\circ} 4,060,386$. Washington: U.S. Patent and Trademark Office.

32. Rout, J., Tripathy, S. S., Nayak, S. K., Misra, M., \& Mohanty, A. K. (2000). Scanning electron microscopy study of chemically modified coir fibers. Journal of Applied Polymer Science, 79(7), 1169-1177. http://dx.doi.org/10.1002/10974628(20010214)79:7<1169::AID-APP30>3.0.CO;2-Q.

33. Rout, J., Misra, M., Tripathy, S. S., Nayak, S. K., \& Mohanty, A. K. (2001). The influence of fibre treatment on the performance of coir-polyester composites. Composites Science and Technology, 61(9), 1303-1310. http://dx.doi.org/10.1016/ S0266-3538(01)00021-5.

34. Shukla, S. R., \& Pai, R. S. (2005). Adsorption of Cu (II), Ni (II) and $\mathrm{Zn}$ (II) on modified jute fibres. Bioresource Technology, 96(13), 1430-1438. PMid:15939269. http://dx.doi.org/10.1016/j. biortech.2004.12.010.

35. Manikandan Nair, K. C., Thomas, S., \& Groeninckx, G. (2001). Thermal and dynamic mechanical analysis of polystyrene composites reinforced with short sisal fibres. Composites Science and Technology, 61(16), 2519-2529. http://dx.doi. org/10.1016/S0266-3538(01)00170-1.

36. Paul, S., Nanda, P., \& Gupta, R. (2003). PhCOCl-Py/basic alumina as a versatile reagent for benzoylation in solventfree conditions. Molecules, 8(4), 374-380. http://dx.doi. org $/ 10.3390 / 80400374$.

37. Arfin, J. M., Mahbubur, R. M., Humayun, K., Md. Alamgir, K., Ahmed, F., Md. Abul, H., \& Md. Abdul, G. (2012). Comparative study of physical and elastic properties of jute and glass fiber reinforced LDPE composites. International Journal of Scientific \& Technology Research, 1(10). 68-72.

38. Vijaya Ramnath, B., Junaid Kohan, S., \& Niranjan Raja, R. (2013). Evaluation of mechanical properties of abaca-jute-glass fibre reinforced epoxy composite. Materials and Design, 51, 357-366. http://dx.doi.org/10.1016/j.matdes.2013.03.102.

39. Florence, A. J., Kennedy, A. R., Shankland, N., Wright, E., \& Al-Rubayi, A. (2000). Norfloxacin dehydrate. Acta
Crystallographica, 56(Pt 11), 1372-1373. http://dx.doi. org/10.1107/S0108270100010933. PMid:11077303.

40. Ferry, J. D. (1980). Viscoelastic properties of polymers (3rd ed.). NewYork: Wiley.

41. Paiva, J. M. F., \& Frollini, E. (2006). Unmodified and modified surface sisal fibers as reinforcement of phenolic and lignophenolic matrices composites: thermal analyses of fibers and composites. Macromolecular Materials and Engineering, 291(4), 405-417. http://dx.doi.org/10.1002/mame.200500334.

42. Pothan, L. A., Oommen, Z., \& Thomas, S. (2003). Dynamic mechanical analysis of banana fiber reinforced polyester composites. Composites Science and Technology, 63(2), 283293. http://dx.doi.org/10.1016/S0266-3538(02)00254-3.

43. Klemm, D., Philipp, B., Heinze, T., Heinze, U., \& Wagenknecht, W. (1998). Comprehensive cellulose chemistry fundamentals and analytical methods (Vol. 1, 2nd ed, pp. 1-20). New York: Wiley-VCH.

44. Hameed, N., Sreekumar, P. A., Francis, B., Yang, W., \& Thomas, S. (2007). Morphology, dynamic mechanical and thermal studies on poly(styrene-co-acrylonitrile) modified epoxy resin/glass fibre composites. Composites. Part A, Applied Science and Manufacturing, 38(12), 2422-2432. http://dx.doi. org/10.1016/j.compositesa.2007.08.009.

45. Joseph, P. V., Mathew, G., Joseph, K., Groeninckx, G., \& Thomas, S. (2003). Dynamic mechanical properties of short sisal fibre reinforced polypropylene composites. Composites. Part A, Applied Science and Manufacturing, 34(3), 275-290. http://dx.doi.org/10.1016/S1359-835X(02)00020-9.

46. Chandra, R., Singh, S. P., \& Gupta, K. (1999). Damping studies in fiber reinforced composites: a review. Composite Structures, 46(1), 41-51. http://dx.doi.org/10.1016/S0263-8223(99)000410 .

47. Idicula, M., Malhotra, S. K., Joseph, K., \& Thomas, S. (2005). Dynamic mechanical analysis of randomly oriented intimately mixed short banana/sisal hybrid fibre reinforced polyester composites. Composites Science and Technology, 65(7-8), 10771087. http://dx.doi.org/10.1016/j.compscitech.2004.10.023.

48. Martínez-Hernández, A. L., Velasco-Santos, C., de-Icaza, M., \& Castaño, V. M. (2007). Dynamical-mechanical and thermal analysis of polymeric composites reinforced with keratin biofibers from chicken feathers. Composites. Part B, Engineering, 38(3), 405-410. http://dx.doi.org/10.1016/j. compositesb.2006.06.013.

49. Qazvini, N. T., \& Mohammadi, N. (2005). Dynamic mechanical analysis of segmental relaxation in unsaturated polyester resin networks: Effect of styrene content. Polymer, 46(21), 90889096. http://dx.doi.org/10.1016/j.polymer.2005.06.118.

50. Alves, N. M., Gomez Ribelles, J. L., Gomez Tejedor, J. A., \& Mano, J. F. (2004). Viscoelastic Behavior of Poly(methyl methacrylate) Networks with Different Cross-Linking Degrees. Macromolecules, 37(10), 3735-3744. http://dx.doi.org/10.1021/ ma035626z.

51. Gu, H. (2009). Dynamic mechanical analysis of the seawater treated glass/polyester composites. Materials \& Design, 30(7), 2774-2777. http://dx.doi.org/10.1016/j.matdes.2008.09.029.

52. Raya, D., Sarkara, B. K., Dasb, S., \& Ranab, A. K. (2002). Mechanical and dynamic mechanical analysis of hybrid composites molded by resin transfer molding. Composites Science and Technology, 62(7-8), 911-917. http://dx.doi. org/10.1016/S0266-3538(02)00005-2.

53. Mallarino, S., Chailan, J. F., \& Vernet, J. L. (2009). Interphase study in cyanate/glass fibre composites using thermo mechanical analysis and micro-thermal analysis. Composites Science and Technology, 69(1), 28-32. http://dx.doi.org/10.1016/j. compscitech.2007.10.043. 
54. Clark, R. L. Jr, Craven, M. D., \& Kander, R. G. (1999). Nylon 66/poly(vinyl pyrrolidone) reinforced composites: 2 Bulk mechanical properties and moisture effects. Composites. Part A, Applied Science and Manufacturing, 30(1), 37-48. http:// dx.doi.org/10.1016/S1359-835X(98)00083-9.

55. Goyanes, S. N., Marconi, J. D., Konig, P. G., Martin, M. D., \& Mondragon, I. (2000). Dynamical properties of epoxy composites filled with quartz powder. Journal of Alloys and Compounds, 310(1-2), 374-377. http://dx.doi.org/10.1016/ S0925-8388(00)00952-X.

56. Jayanarayanan, K., Thomas, S., \& Joseph, K. (2008). Morphology, static and dynamic mechanical properties of in situ micro fibrillar composites based on polypropylene/poly (ethylene terephthalate) blends. Composites. Part A, Applied Science and Manufacturing, 39(2), 164-175. http://dx.doi. org/10.1016/j.compositesa.2007.11.008.

57. Kaddami, H., Dufresne, A., Khelifi, B., Bendahou, A., Taourirte, M., Raihane, M., Issartel, N., Sautereau, H., Gérard, J.-F., \& Sami, N. (2006). Short palm tree fibers - Thermoset matrices composites. Composites. Part A, Applied Science and Manufacturing, 37(9), 1413-1422. http://dx.doi.org/10.1016/j. compositesa.2005.06.020.

58. Pothan, L. A., Thomas, S., \& Groeninckx, G. (2006). The role of fibre/matrix interactions on the dynamic mechanical properties of chemically modified banana fibre/polyester composites. Composites. Part A, Applied Science and Manufacturing, 37(9), 1260-1269. http://dx.doi.org/10.1016/j.compositesa.2005.09.001.

59. Mallarino, S., Chailan, J. F., \& Vernet, J. L. (2005). Glass fibre sizing effect on dynamic mechanical properties of cyanate ester composites I. Single frequency investigations. European Polymer Journal, 41(8), 1804-1811. http://dx.doi.org/10.1016/j eurpolymj.2005.02.022.
60. Singh, V., Tiwari, A., Tripathi, D. N., \& Sanghi, R. (2004). Grafting of poly acrylonitrile onto guar gum under microwave irradiation. Journal of Applied Polymer Science, 92(3), 15691575. http://dx.doi.org/10.1002/app.20099.

61. Singh, V., Tripathi, D. N., Tiwari, A., \& Sanghi, R. (2004). Microwave promoted synthesis of chitosan-graft-poly (acrylonitrile). Journal of Applied Polymer Science, 95(4), 820-825. http://dx.doi.org/10.1002/app.21245.

62. Kaith, B. S., Singha, A. S., \& Gupta, S. K. (2003). Graft copolymerization of Flax fibres with binary vinyl monomer mixtures and evaluation of swelling, moisture absorbance and thermal behavior of the grafted fibres. Journal of Polymer Materials, 20, 195-199.

63. Princi, E., Vicini, S., Pedemonte, E., Mulas, A., Franceschi, E., Luciano, G., \& Trefiletti, V. (2005). Thermal analysis and characterisation of cellulose grafted with acrylic monomers. Thermochimica Acta, 425(1-2), 173-179. http://dx.doi. org/10.1016/j.tca.2004.07.001.

64. Kaith, B.S., Singha, A.S., \& Kalia, S. (2006). Mechanical properties of Raw Flax and Flax- g-poly (MMA) reinforced phenol-formaldehyde composites. International Journal of Plastics Technology, 10, 572-587. http://dx.doi.org/10.1007/ s12588-009-0045-3.

65. Geethamma, V. G., Joseph, R., \& Thomas, S. (1995). Short coir fiber-reinforced natural rubber composites: effects of fiber length, orientation, and alkali treatment. Journal of Applied Polymer Science, 55(4), 583-594. http://dx.doi.org/10.1002/ app.1995.070550405.

Received: Apr. 20, 2016

Revised: June 29, 2016

Accepted: July 12, 2016 